\title{
EL ESPECTADOR LAS PREFIERE EN CASA
}

\section{THE VIEWER PREFERS AT HOME}

Susana Salcedo Peris: Universidad Complutense de Madrid. (España) susalpe@hotmail.com

\section{CURRÍCULUM VITAE}

Licenciada en Comunicación Audiovisual por la Facultad de Ciencias de la Información de la Universidad Complutense de Madrid (España). Miembro de Fórum XII de Comunicación y Relaciones Públicas y de la SEECI (Sociedad Española de Estudios de la Comunicación Iberoamericana)

\section{RESUMEN}

En la página web del Ministerio de Cultura, salieron el 10-03-09 los datos oficiales sobre España en 2008 en cuanto a la cantidad de espectadores que fueron al cine, la recaudación de las películas y el número de salas de proyección existentes. Los datos son escalofriantes, pero no sólo a lo que se refiere al año en sí, que también, sino por lo que auguran sobre cómo serán los próximos.

\section{PALABRAS CLAVE}

Cine - Espectadores - Recaudación - Previsiones 


\section{ABSTRACT}

On the website of the Ministry of Culture, came the official data on 03/10/09 Spain in 2008 as to the amount of spectators who went to the movies, collecting movies and the number of cinemas available. The data are chilling, but not only as regards the year itself, that too, but for what they predict how will be next.

\section{KEY WORDS}

Film - Viewers - Collection - Forecasts

\section{TEXTO}

En la página web del Ministerio de Cultura, salieron el 10-03-09 los datos oficiales sobre España en 2008 en cuanto a la cantidad de espectadores que fueron al cine, la recaudación de las películas y el número de salas de proyección existentes. Los datos son escalofriantes, pero no sólo a lo que se refiere al año en sí, que también, sino por lo que auguran sobre cómo serán los próximos.

En cuanto al número de espectadores, fueron al cine un total de 107.813.259 personas, lo que supone 9.117.033 menos que en 2007.

El número total de largometrajes exhibidos fue de 1.652, es decir, 124 menos que en 2007 (394 españoles y 1.258 extranjeros). Hay 8 películas españolas más, que el año anterior. 
La recaudación total en taquilla alcanzó los 619,29 millones de $€$, lo que supone un descenso de 24,4 millones con respecto a 2007. De estas cifras, 81,6 millones corresponden al cine español, 5 millones menos que en 2007.

Respecto a las salas de proyección, quedan 868 cines, 39 menos respecto al año pasado.

Podría continuar poniéndoles más datos que seguirían en la misma línea que los anteriores, pero considero que estos ya son suficientes para hacernos una idea del declive que sufre el cine en general (no sólo el cine español).

Respecto a las películas más taquilleras, estos son los datos:

-“Los crímenes de Oxford” fue la película de producción nacional que más recaudación logró en 2008 (8,2 millones de $€$ ), fue vista por 1,4 millones de espectadores y ocupa el décimoquinto puesto en la clasificación de taquilla. Sus predecesoras (la mayoría estadounidenses): “India Jones y el reino de la calavera de cristal" ocupa el primer puesto. Ganó 20,8 millones de euros y fue vista por 3,5 millones de espectadores.

-La segunda película española más vista fue “Mortadelo y Filemón: misión salvar la Tierra", que ocupa el puesto $16^{\circ}$, seguida por "Vicky Cristina Barcelona" (puesto $\left.19^{\circ}\right)$ y “Che, el argentino" (24 a posición).

-La película que triunfó en los premios Goya, "Camino", fue vista en 2008 por 215.000 personas y ocupaba el puesto $11^{\circ}$ entre los largometrajes.

Tras estos datos cabe plantearse ¿Qué ha pasado? ¿Por qué el cine que no hace muchos años era un medio con vistas hacia un futuro aún más prometedor del que 
ya gozaba, bucea ahora hacia el desastre? Puesto que todavía sólo soy una espectadora más, aunque este tema me preocupa especialmente, he observado con detenimiento a mi alrededor $\mathrm{y}$ he buscado en mi experiencia propia para poder darme una razón a mi misma y no pensar que esto simplemente es un mal sueño y que el tiempo hará que todo se arregle. Las cosas no funcionan así. Hay hechos que son irrefutables. Y hay cosas que nunca se arreglan. Esperemos que este no sea el caso, pero de momento los datos son demoledores y el cine está pidiendo auxilio en un grito agónico que dice: "Cambio".

Hagamos un repaso de por qué el ciudadano medio, un sábado por la noche, le es más usual quedarse en casa viendo una película que ir al cine. Los precios desorbitados de las entradas nos sangran. Analicemos este tema más en profundidad. Según un análisis realizado por la organización de consumidores Facua en 2008 a partir de 128 cines en 33 ciudades de las 17 comunidades autónomas, el precio medio de una entrada de cine en 2008 se sitúa en 5,75€, es decir, aumenta en un $6,3 \%$ con respecto al año anterior, puesto que en 2007, el precio medio de una entrada en días laborables era de 5,41€; en 2006, 5,22€; en 2005, 5,05€, y en 2004, 4,80€. Pero aún hay más. Entre los diferentes cines analizados se encontraron diferencias de precio de hasta el 160\%. Así, oscilan entre 3 euros y 7,80 euros, según el cine al que vayas. Las ciudades más caras son Barcelona (una entrada cuesta de media 7,14€ en días laborables), Madrid (6,98€ de media), Santa Cruz de Tenerife $(6,70 €$ de media) y Oviedo (6,70€ de media), y las más baratas Cádiz (4,35€ de media), Jaén $(4,50 €$ de media) y Córdoba (4,53€ de media). Dentro de una misma ciudad, los consumidores pueden encontrar diferencias en los precios de los cines de hasta el 123\%. Un ejemplo de esto es el caso de Valencia, donde la entrada un día normal puede costar desde 3,00€ hasta 6,70€. La gran mayoría de los cines ofrecen precios especiales en determinados días de la semana, como el del espectador y horarios de sesiones matinales y de madrugada. El día del espectador, que varía según la ciudad (aunque la gran mayoría de los cines encuestados se decantan por el lunes o el miércoles), 
cuesta $4,88 €$ de media en los cines que ofrecen esta tarifa reducida (111 de los 128 analizados).

Bien, después de este análisis quizá se entienda mejor mis expresión de "las entradas nos sangran", porque lo hacen casi literalmente. Los precios van en aumento y no tienen ninguna intención parar. Supongamos que hemos pagado esa entrada, y nos disponemos a elegir la película que veremos. Por estadística, a no ser que ciertas películas españolas hayan tenido una buena crítica o sus directores tengan ya prestigio en el medio o cuenten con actores de renombre, la mayoría de espectadores mira primero entre las películas extranjeras. Los españoles no quieren ver cine español. ¿Por qué? Las razones que más se escuchan van del estilo de: "es un cine malo", "no tiene el nivel de las películas estadounidenses", "no tenemos imaginación", "falta espectacularidad", "aquí los entornos en las películas son deprimentes y los estadounidenses hasta lo cutre te lo ofrecen con cierto brillo y cierta luz" "siempre estamos recordando el pasado", "la mayoría de películas van sobre la Guerra Civil”. No podemos comparar nuestro cine con el de E.E.U.U (porgo este ejemplo por ser el más esclarecedor). También es cierto que nuestro deber es ser críticos y para ello, hay que comparar. Y si consideramos que ese cine es el que más se acerca al nivel más alto que existe actualmente, lo lógico es que queramos que nuestro cine español se parezca lo más posible. Pero pensemos. En E.E.U.U. se hacen infinidad, pero infinidad de películas. A nosotros sólo llegan "unas pocas" (aunque creamos que llegan muchísimas) por lo que su grado de filtración es mucho mayor que en España. Sí tenemos imaginación. ¡Claro que sí! De hecho ahora pienso en una gran cantidad de títulos españoles magníficos..., pero es cierto que mi pensamiento siguiente es: "si esta película fuera extranjera, habría sido considerada una muy buena película, quizá a nivel mundial". Es una pena. Nuestro halo "a la española" si nota en muchos films y no tiene muy buena acogida. ¡Pero es que somos españoles! También se nota el halo "a lo E.E.U.U." o "a la francesa” por poner otro ejemplo. Esto no debería de ser peyorativo, ni si quiera deberían existir halos. Todos somos 
individuales y nos nutrimos de nuestro cine y el de otros países. Pero sin querer los hay (los halos), y si no los hay, ya se encarga la critica de meterte en algún saco. Recapitulemos pues, somos ese espectador que entra en el cine a ver una película. Nos sentamos en nuestra butaca, y el cine empieza a llenarse (aunque no demasiado). Gente a nuestra derecha y a nuestra izquierda. Delante y detrás. Empieza la película. Y con ella sus ruidos típicos de las palomitas, bolsas de patatas..., comentarios, risas inoportunas, los niños (y no tan niños) sin parar de moverse...

La gente quiere ahorrarse todo esto. No les importa perder en espectacularidad y calidad, ni por supuesto el dinero que pierden los productores de la película..., si pueden estar tranquilos en sus casas, haciendo el ruido que quieran, levantándose las veces que haga falta y parando el video media hora y además todo esto, gratis. Efectivamente. Las famosas descargas son una realidad, y eMule se ha convertido en el programa perfecto para que todas estas penalidades desaparezcan. Ir al cine siempre ha sido un acto social, pero ahora está cayendo en desuso. Actualmente ya no se queda para tomar algo y luego ir al cine, sino que se queda en un bar y luego se van todos a una casa para ver la última película que se han descargado.

El cine tiene que adaptarse a las nuevas actitudes que con respecto a él, la gente empieza a tomar como habituales. Ha de cambiar su grado de enfoque. Plantearse nuevas metas. Y tenemos que ayudarlo para que lo consiga. Poniendo un precio tan alto a las entradas, no es una solución. Lo mismo ocurre con la música. El negocio ahora está en los conciertos. ¿Y el cine?

Ojalá el medio encuentre una vía de escape para salvarse, o pasemos ya a otro nivel, otra escala. Quizá todas las salas de cine estén condenadas a desaparecer. Quizá se proyecten los estrenos desde nuestros ordenadores mientras estamos tumbados en nuestra cama. O quizá todo de la vuelta y pasemos a una era virtual como pretende 
James Cameron y los cines salgan de las cenizas que los tiñen de gris. La historia se abre paso, y el cine forma parte de ella en una inmensa proporción. Lo conseguirá.

Webgrafía:

http:/ / ecodiario.eleconomista.es/sociedad/noticias/874425/11/08/El-preciomedio-de-una-entrada-de-cine-es-de-575-euros-un-63-mas-que-el-ano-pasado.html

http:/ / www.mcu.es/cine/MC/CDC/Anio2008.html

http://www.elpais.com/articulo/cultura/cine/espanol/perdio/millones/espectad ores/2008/elpepucul/20090312elpepucul_1/Tes

http:/ / www.filmica.com/delafuente/archivos/005619.html

http:/ / www.actualidadcine.com/2009/03/12/el-cine-pierde-espectadoresrenovarse-o-morir/

http:/ / www.marketingdirecto.com/noticias/ noticia.php?idnoticia=32484\&origen=t eletipo 